\title{
When Team Identity Helps Innovation and When it Hurts: Team Identity and its Relationship to Team and Cross-team Innovative Behavior*
}

\author{
Robert C. Litchfield \\ Department of Economics and Business \\ Washington \& Jefferson College \\ Zahide Karakitapoğlu-Aygün \\ Lale Gumusluoglu \\ Faculty of Business Administration \\ Bilkent University \\ Matthew Carter \\ Aston Business School \\ Aston University \\ Giles Hirst \\ College of Business \& Economics \\ Australian National University
}

Address correspondence to: Robert C. Litchfield, Department of Economics and Business, Washington \& Jefferson College, 60 S. Lincoln St., Washington PA, 15301 USA

Email: rlitchfield@washjeff.edu. Tel: 724-250-3392

*This work was supported by The Scientific and Technological Research Council of Turkey (TUBITAK) [Grant number 107K439]. An earlier version of this paper was also presented at the 2013 Academy of Management annual conference in Orlando Florida. The authors wish to thank Dean Tjosvold and Qin Zhou for useful comments on earlier versions of this paper. 


\begin{abstract}
Author Bios
Robert C. Litchfield is an associate professor in the Department of Economics and Business at Washington \& Jefferson College. He received his Ph.D. in industrial/organizational psychology from The Ohio State University. Rob's research focuses on creativity and innovation and in particular seeks to understand how motivational forces shape the generation, development, and use of creative ideas.
\end{abstract}

Zahide Karakitapoglu-Aygün is an associate professor at Faculty of Business Administration at Bilkent University. Her research interests include commitment, transformational leadership, paternalistic leadership, organizational justice, team innovation and team processes. She published in several journals such as Journal of Cross-Cultural Psychology, Personality and Social Psychology Bulletin, Leadership, Journal of Business Ethics, European Journal of Social Psychology, Journal of Social Psychology and Journal of Business Research.

Lale Gumusluoglu is an assistant professor at Faculty of Business Administration at Bilkent University. Her research interests include leadership, knowledge workers, individual and teamlevel innovation \& creativity, commitment and justice. Her articles were published in journals such as Journal of Product Innovation Management, Journal of Business Research, Leadership and European Management Review.

Matthew Carter is currently a senior research fellow in the Work and Organizational Psychology Department at Aston Business School, Aston University. His research interests include team process, work design and performance. He has published in several journals such as Journal of Organizational Behavior, International Journal of Human Resource Management, and European Journal of Work and Organizational Psychology.

Giles Hirst is Chair of Leadership at the Australian National University. Giles serves on the editorial boards of The British Journal of Management, The Journal of Organizational Behavior and The Journal of Personnel Psychology. He has published in The Journal of International Business Studies, The Journal of Applied Psychology, The Academy of Management Journal, The Leadership Quarterly and The Journal of Organizational Behavior. He has received more than $\$ 800,000$ of research grants and more than half a million dollars of industry research funding. He studies leadership, creativity and innovation. 


\begin{abstract}
Although the success of team-based organizations requires innovative behavior within and across teams, little research has considered how to foster both types of activity. This is problematic as strong team attachments such as team identification may have mixed effects on team innovative behavior, and may even negatively impact cross-team innovative behavior. The present research explains these mixed effects through intra- and intergroup aspects of social identity theory and the concept of team reflexivity. Effects of team identification on team innovative behavior were expected to be contingent upon team reflexivity, such that team identification would be positively related to team innovative behavior only when team reflexivity was high. Where a team's innovative behavior involves working across team boundaries with other teams, i.e. crossteam innovative behavior, this interaction between team identification and reflexivity was further expected to be qualified by perceived interdependence with another team. In a sample of 61 Turkish research and development (R\&D) teams comprising 305 employees and 61 team leaders, the association between team identity and team innovative behavior was moderated by team reflexivity as predicted. Further, team identity was positively associated with cross-team innovative behavior only when reflexivity and perceived interdependence between teams were both high, and negatively associated when reflexivity was low and perceived interdependence between teams was high.
\end{abstract}

Keywords: Team identity, team innovative behavior, cross-team innovative behavior, reflexivity, perceived interdependence, intergroup behavior

Practitioner Points:

*Team identity does little to benefit innovative behavior and can actually harm it across teams if unaccompanied by collective reflection.

* Managers should work to increase team identity and reflexivity in tandem through practices such as participation in decision making.

*Cueing teams to perceive themselves as interdependent with other teams in multiteam systems is most likely to benefit innovative behavior when individual teams' identities are strong and teams engage in collective reflection. 
When does a stronger team bond lead to innovative behavior? A significant body of research suggests that some type of psychological attachment of individuals to their teams is beneficial to innovation on average (for meta-analyses, see Hülsheger, Anderson, and Salgado, 2009; Sivasubramaniam, Liebowitz, and Lackman, 2012), but there is also a longstanding recognition that team bonds may fail to encourage innovative behavior (e.g., the "isolationist" teams identified by Ancona and Caldwell, 1992). Team identification, a strong form of attachment where individuals partially derive their self-definition from the team, exhibits particularly mixed effects on innovation-related behaviors (cf., Hirst, van Dick, and van Knippenberg, 2009a; Janssen and Huang, 2008; Glynn, Kazanjian, and Drazin, 2010). Although team identification motivates individuals to act on the team's behalf, it does not necessarily encourage them to engage in innovative behavior. Innovative behavior is concerned with doing things differently and changing approaches; highly-identified teams may or not be inclined to engage in such actions. Negative effects of team psychological attachment have repeatedly been reported in contexts where teams need to engage in innovative behavior across the team boundary (Ancona and Caldwell, 1992; Dougherty and Heller, 1994; Glynn et al., 2010), yet existing research does not differentiate innovative behavior focused within versus across teams. Understanding this variation is important because multi-team contexts are becoming more typical yet many organizations do little to support teams within these structures (Barczak, Griffin, and Kahn, 2009). From a strategic innovation perspective, understanding the drivers of innovative behavior within and across the team boundary is critical as teams need to engage internally in innovative behavior and it is rare for large scale innovation to rely on just one team. In complex innovation projects such as aircraft design, R\&D teams' work frequently bumps up against that of other R\&D teams. For instance, the work of avionics and cable harness design 
teams intersects in the placement and technology of flight recorders in an aircraft. In this article, we seek to clarify conditions under which team identification will be likely to energize teamlevel innovative behavior within and across the team boundary.

To understand the role of attachments of team members to their team as antecendents of both team- and cross-team innovative behavior we focus on team identity (i.e., team identification at the team level; Lembke and Wilson, 1998) and use social identity theory. We leverage the concept of team reflexivity to explain when strong team identities will be likely to lead to team innovative behavior. Based on intergroup theory (Sherif, Harvey, White, Hood, and Sherif, 1961), we also consider the role of perceived interteam interdependence in determining when effects of team identity will extend to cross-team innovative behavior. Social identity theory proposes that strong identification with a team will motivate behavior that is perceived as consistent with that team's identity, and that this perception of consistency is determined not by a team's goals themselves but rather by a team's recognition of what behavior will maintain team identity while pursuing its goals (Ellemers, De Gilder, and Haslam, 2004; Pettigrew and Tropp, 2006). In R\&D contexts where innovative behavior is integral to team performance, a strong team identity might be expected to exert some positive force toward team innovative behavior (Markham and Lee, 2014; Mascitelli, 2000). However, the introduction of novelty and therefore risk to a team's routines might also be seen as threatening even when innovation is important (Ancona and Caldwell, 1992; Dougherty and Heller, 1994). A social identity approach recognizes that if a team construes novelty as a threat, a strong team identity will not be likely to lead to innovative behavior (Janssen and Huang, 2008). Taking both views of team identity effects into account suggests that even when a team's formal role focuses on innovation, it may or may not reliably recognize innovative behavior as identity-consistent. For a strong team 
identity to reliably increase team-level innovative behavior, teams require processes that serve as a collective reminder that innovative behavior is identity-consistent and important to achieving team goals. In short, teams need processes that legitimize innovative behavior (Dougherty and Heller, 1994). Such processes have been described in the teams literature as reflexivity (Schippers, West, and Dawson, 2015; West, 1996; 2000). Reflexive teams routinely reflect on their processes and strategies for meeting goals in order to adapt to their changing environments (West, 1996). As a result, highly reflexive teams develop more sophisticated views of their task environments and are more likely to see how innovative behavior can strengthen the team and its performance on complex problems (West, 2000). Hence, team reflexivity serves the legitimizing role that renders team innovative behavior identity-consistent and energizes its expression.

Although managers may expect $\mathrm{R} \& \mathrm{D}$ teams to engage in innovative behavior across the team boundary toward other teams (Barczak et al. 2009), research suggests that most teams will shun such intergroup behavior unless they perceive that their own success is somehow dependent on another team (Gaertner et al., 2000; Hewstone, Rubin, and Willis, 2002). Thus, any effects of team identity on innovative behavior across the team boundary depend upon the extent to which a team perceives interdependence with another team. Intergroup literature additionally shows that, when a team perceives it is dependent upon another team, a strong team identity could lead to either positive or negative effects on cross-team behavior (Gaertner et al., 2000; Sherif et al., 1961). On the positive side, teams that consider how their work meshes with that of other teams may better develop mutual respect and good working relations resulting in cooperative behaviors (Gaertner et al., 2000; Hewstone et al., 2002). Yet, when teams do not engage in adaptive thinking about their task environment, they may perceive other interdependent teams as threats to their identity. This may trigger intergroup competition and may reduce the likelihood of 
innovative behavior that crosses the team boundary (Glynn et al., 2010). Extending social identity theorizing, we propose that team reflexivity describes such adaptive thinking about higher-order aspects of the task environment that intergroup treatments of social identity theory have found to differentially affect intergroup behavior (cf., Gaertner et al., 2000; West, 1996; 2000). In other words, it is reflexivity that leads to either positive or negative effects on crossteam innovative behavior for strongly identified, interdependent teams. We address social identity theory's ambiguity about intergroup effects by proposing that team reflexivity can make this difference between positive and negative effects of team identity on cross-team innovative behavior in teams that perceive interdependence with others by increasing the likelihood that such teams will frame task and role definitions in their work in ways that legitimize cross-team innovative behavior as identity-consistent.

The study reported here, the first to examine both team identification and innovative behavior at the team level, explains when innovative behavior will be motivated by strong team identity by examining the interaction between team identity and team reflexivity. By differentiating team and cross-team innovative behavior and leveraging the interteam concept of perceived interdependence, this study also illuminates when and how the interaction between identity and reflexivity is likely to generalize to cross-team innovative behavior. In doing so this work advances theory and speaks to prominent calls to understand innovation within and across team interfaces (Anderson, Potocnik, and Zhou, 2014) utilizing the natural starting point of the team level of analysis. 


\section{Literature Review and Hypotheses}

\section{Innovative Behavior}

Innovative behavior is the intentional introduction and application of new ideas, products, processes and procedures to work roles, units or organizations (West and Farr, 1990). Organizations have increasingly implemented teams as the primary unit to develop new innovations (Hülsheger et al., 2009), relying on team innovative behavior to drive the intentional introduction and application of new ideas, products, processes and procedures by a team within its domain of operation (West, 2002). This general concept of team innovative behavior does not differentiate innovative behavior within a team's boundaries from innovative behavior that involves other teams. This is important because it is common for teams to work together to produce larger innovative products (Glynn et al., 2010) and yet observers indicate that innovative behavior within teams is not necessarily associated with innovative behavior across the team boundary (Ancona and Caldwell, 1992; Dougherty and Heller, 1994). Accordingly, we propose that team and cross-team innovative behaviors constitute different patterns and processes.

Several research streams converge on this insight that within-team and cross-team behaviors are distinct. For instance, research on multi-team systems (Mathieu, Marks and Zaccaro 2001), team boundary-spanning behaviors (Marrone, 2010), and intergroup theories in social psychology (Ellemers et al., 2004; Pettigrew and Tropp, 2006) all regard behavior between teams as differentiated from behavior that occurs within them. In particular, the boundary spanning literature suggests that cross-boundary interactions with other teams provide an effective means of acquiring knowledge, resources and support necessary for team and organizational performance and innovation (Ancona and Caldwell, 1992; Drach-Zahavy and Somech, 2010; Faraj and Yan, 2009; Hargadon, 1998; Marrone, 2010). 
Drawing on such diverse perspectives, Richter and colleagues (Richter, Scully, and West, 2005; Richter et al., 2006) proposed a general and integrative framework for intergroup effectiveness. They argue that cross-team behaviors in organizations are driven by teams' need for resources and/or to respond to organization-level demands for cooperation (Richter et al., 2005). Whereas team innovative behaviors are concerned with directly creating, developing, and implementing new ideas to accomplish the team's work, the general inter-team effectiveness work of Richter and colleagues suggests that "groups may be most likely to cooperate in order to both provide each other with valuable resources and to work on collaborative mandates, problems, or opportunities” (2005, p. 184). In line with Richter and colleagues' general interteam framework, we argue that in a multi-team innovation context such as with R\&D teams, crossteam innovative behavior will be focused on obtaining resources such as time, staff, and ideas to support the team's internal efforts and contextualizing the team's efforts in light of broader organizational demands for cooperation toward innovation through actions such as allocating roles and tasks and responding to problems common to organizational innovation projects. These activities, such as subdividing an innovation problem between teams and acquiring ideas and knowledge from another team, are potentially important innovative behaviors (Amabile, 1988) and are consistent with the task coordination activities found by Ancona and Caldwell (1992) to be most associated with innovation. We therefore define cross-team innovative behavior as intentionally working with other teams to obtain ideas and resources and coordinate work to facilitate innovation development and implementation relevant to the team's work.

\section{Team Identity and Team Innovative Behavior}

Team identification refers to the extent to which the individual defines the self in terms of his/her membership in a particular team (van Knippenberg and van Schie, 2000). Although 
identification is at root an individual level construct, the social identity approach (Haslam, 2004; Hogg and Terry, 2000) recognizes that social identification often is a socially shared state. The reason for this is twofold. First, many influences on social identification external to the team, such as the team's prestige or intergroup competition (Ashforth and Mael, 1989; Tajfel and Turner, 1986), are typically shared influences for all group members. Second, group interaction may have a shared influence internal to the team, affecting team member identification (cf., Morgeson and Hofmann, 1999). An increasing body of research articulates both a theoretical and empirical case for the study of collective-level identification with a team, calling it team identity (see: Gundlach, Zivnuska, and Stoner, 2006; Lembke and Wilson, 1998; Mitchell, Parker \& Giles, 2011; Somech, Desivilya, and Lidogoster, 2009). Team identity, measured as a grouplevel aggregation of individual members' team identification, unifies team members into a socially identifiable whole and encourages members to favor activities that benefit the group's interests (Gundlach et al., 2006; Mitchell et al., 2011; Somech et al., 2009).

Three studies, all focused on individual level of analysis, have examined team identification and its role in fostering either creative or innovative behavior to date, but they return inconsistent findings. In the first, Janssen and Huang (2008) found that team identification enhanced citizenship behavior in a team but was unrelated to creative behavior. Instead, individual differentiation (i.e., perceptions of individuality in terms of thoughts, feelings and behaviors) predicted the extent to which team members came up with unique ideas. The authors concluded that since team identification fosters conformity rather than creativity, team members need a strong sense of individuality as a complementary driver to be able to produce creative ideas that are different from beliefs and values in the team. Yet in another study, Hirst et al. (2009a) found that team identification at the individual level positively affected creative behavior 
through creative effort in a sample of pharmaceutical R\&D workers. They argued that identification encourages persistence and creative effort when creativity is highly valued since identification encourages members to view task accomplishment as important. Finally, Glynn et al. (2010) conducted a novel study of a complex, multi-team context finding that team identification interacted with perceived interdependence. Employees who strongly identified with their team and perceived that their team was interdependent with other teams reported lower intentions to innovate. Interestingly, structural interdependence imposed by the organization did not affect innovation intentions - only perceptions of interdependence by employees mattered. The authors concluded that team identification leads individuals to perceive interdependence with another team as a threat, diverting their attention from innovation. This study suggests perceived interdependence as an important condition determining whether increasing identification can actually undermine innovation activities involving other teams.

Although these three prior studies were individual as opposed to team level studies, the divergent results resonate with social identity theory and our theorizing. Specifically, social identity theories propose that identification leads teams to pursue goals in ways that are consistent with their identities (Ellemers et al., 2004). In this regard, a variety of behaviors may come to be viewed as identity-consistent in teams depending upon a team's processes (Hewstone and Brown, 1986), and a team's construal of its roles and relationships can lead it to view as identity-consistent behaviors that are not very helpful in reaching team goals (Gaertner et al., 2000). For instance, the expression of new ideas may not be identity-consistent even in many teams that "appreciate creativity" (Janssen and Huang, 2008, p. 72). Adarves-Yorno, Postmes and Haslam (2006) showed that ideas in a group are more likely to be seen as creative to the extent that they are congruent with group norms of creativity. The narrower the group's latitude 
of acceptance, the more likely it is that a novel idea will be rejected. In other words, group norms of creativity play a pivotal role in determining the group's creativity (Goncalo and Staw, 2006) and may facilitate creativity's recognition as identity-consistent behavior. In sum, team identity directs efforts toward maintaining the status of the team, but a strong identity alone provides little indication that innovative behavior will be motivated because a team may or may not view such behavior as a way to reach its goals while maintaining its identity. Together, literature suggests that the effect of strong team identity on team innovative behavior depends on whether this behavior is seen as identity-consistent. We propose that team reflexivity is a mechanism that tends to increase teams' perceptions that team innovative behavior is identity-consistent, and further expand this notion to include perceived team interdependence when considering innovative behavior across teams. We explain our thinking below.

\section{The Role of Reflexivity}

Team reflexivity is defined as "the extent to which team members overtly reflect upon the group's objectives, strategies and processes and adapt them to current anticipated endogenous or environmental circumstances" (West, 1996, p. 559). In developing the reflexivity concept, West (2000) reframed individual-level work on active reflection by Schön (1983) and Kahn (1992) at the team level to explain how teams differ in their handling of complex and uncertain task environments where innovation is expected. West (2000) proposed that reflexive teams spend time and effort explicitly unpacking assumptions and ideas and using them to build a collective understanding of their task environment and their work within it, and this leads them to view adaptive and innovative behaviors as legitimate paths to team performance. In contrast, nonreflexive teams may regard adaptive and innovative behaviors as threats to the team's ability to efficiently manage its workload because they have prioritized responding to short term demands 
over developing a deeper understanding of their task environment and consequently fail to see how such behaviors could make the team more effective (West, 2000). Reflexive teams are more likely to attend to and build upon the comments and actions of others, gather and share information about changing internal and external conditions, address differences of opinion, question problem-solving assumptions, incorporate new solutions to their problems, change the team's knowledge base and develop new techniques to perform better (De Dreu, 2006; Gong, Kim, Lee, and Zhu, 2013; Hirst, van Knippenberg, and Zhou, 2009b; Hoegl and Parboteeah, 2006; Schippers et al., 2015).

The underlying theory of reflective practice (Schön, 1983) focuses on professionals with strong work identities and suggests that reflective techniques may particularly help such individuals to channel the motivation provided by their identities, encouraging them to view learning, creativity, and questioning of status quo thinking as essential to high performance and as identity-consistent. This theme is especially prominent in a study of the development of reflective practice at the team level in an elite consulting firm, where reflection certainly benefits from and may indeed require a strong sense of collective identity to produce team-level results (Argyris, 1993). In this context, a manager learned to inquire about subordinates' perspectives and to accept their concerns as potentially valid - and as consistent with rather than threatening to managerial identity (Argyris, 1993). Such reflection legitimizes an openness to new ideas and new behaviors as identity-consistent. In comparison, non-reflective individuals and groups tend to frame hard problems requiring innovative behavior as threats to self-views, linking them implicitly to identity concerns even though the word "identity" is not used (Argyris, 1991; West, 2000). This threat framing leads nonreflective individuals to focus narrowly on coping with the identity threat and to adopt a defensive reasoning where they do not test their ideas, inferences 
and conclusions appropriately (Argyris, 1991; West, 2000; for review of identity threat responses, see Petriglieri, 2011). As a result, non-reflective individuals are less likely to view innovative behavior as helpful in maintaining their identity.

From a social identity perspective, the process of building a collective understanding that legitimizes adaptive and innovative behaviors as performance strategies, labeled reflexivity by West (2000), can be described as a process wherein teams come to understand innovative behavior as identity-consistent. Reflexivity acts in conjunction with a strong team identity to enlarge a team's view of what behaviors are consistent with maintaining that identity. This enlargement happens because reflexivity's adaptive approach to understanding group tasks and goals encourages the team to develop a more sophisticated view of its task environment. As reflection develops this more sophisticated view of the task environment, teams are more likely to recognize that innovative behavior, even if it may disrupt short term priorities, serves the team's overarching mission and supports its identity. Reflexivity is essential because identities motivate behavior that is perceived to be identity-consistent and suppress behavior that is viewed as inconsistent with maintaining the identity (Ashforth and Mael, 1989). Without reflexivity, innovative behavior may be seen as less identity-consistent and therefore less motivated by strong team identity.

Team reflexivity requires individuals to engage in behaviors that have the potential to cause them to stand out in a group (West, 2000), and social identity theories note that people pursue a balance between standing out as individuals and blending in to groups (Brewer and Gardner, 1996). Accordingly, teams may be best positioned to leverage their identities when members feel both integrated into the group and respected as individuals (Leonardelli, Pickett, and Brewer, 2010) - feelings that reflexivity seems likely to facilitate. Reflexivity helps the team 
collectively think about the relation between self and group that is central to the functional expression of social identity and specifically legitimizes the distinctiveness of the individual without compromising inclusion in the group (Brewer and Gardner, 1996; Ellemers et al., 2004). In sum, we propose that reflexivity moderates effects of team identity encouraging the team to view approaches that are different or novel and potentially challenge the status quo as beneficial and identity consistent. It provides a context where distinctive opinions can be expressed, sparking innovative behavior. Thus we propose:

Hypothesis 1: Reflexivity moderates effects of team identity on team innovative behavior such that team identity will be most positively associated with team innovative behavior when reflexivity is high.

\section{Perceived Interteam Interdependence and Cross-team Innovative Behavior}

Teams do not always perceive the need to interact with one another even in $R \& D$ structures designed to encourage or require such collaboration (e.g., Ancona and Caldwell, 1992). Although interdependence with another team has long been recognized as a trigger to intergroup effects (Sherif et al., 1961), Glynn et al.'s (2010) finding that perceptual but not structural interdependence affected intentions to innovate in product development highlights the importance of perceived interdependence as crucial to understanding its effects in applied contexts. According to social identity theory, behavior that crosses the team boundary is driven just like any other team behavior - by the team's perception of whether such behavior is consistent with sustaining or enhancing its own identity (Ellemers et al., 2004; Hewstone et al., 2002). Without the perception that a team is dependent upon another team to attain goals that will help it to verify team identity, a social identity approach suggests a team would not reliably engage in any particular behavior across the team boundary because such interactions would not 
be seen as beneficial. As a result, effects of team identity on cross-team innovative behavior are expected to be contingent on the degree of perceived interdependence with another team.

Although Glynn et al. (2010) found that individuals who were highly identified with their team reduced their intentions to innovate when they perceived interteam interdependence, research on social identity and intergroup behavior (for review, see Hewstone et al., 2002) suggests that team identity may spark either positive or negative cross-team behaviors in situations where one highly identified group finds itself dependent on another group to attain its goals. Social identity theory is concerned with implications of the strength of attachment to groups, and research on its intergroup applications does not directly theorize the cognitive mechanism that determines whether these effects are positive or negative. However, intergroup applications of social identity theory do reference the key characteristics of conceptualizing and considering the experience and expertise of the other team and how these may be of use in attaining the focal team's goals in the task environment (Hewstone et al., 2002), and these are very much in line with the process of adaptive and sophisticated representation of task environments described by team reflexivity (West, 2000). As we noted in our discussion of its role in fostering innovative behavior within teams, reflexivity plays an important role enlarging the team's perception of what behaviors are identity-consistent. With cross-team behavior, reflexivity encourages an interdependent team to look across the team boundary as a part of a more complex task framing and therefore to consider cross-team innovative behaviors as legitimate, identity-consistent means to meet team goals. Hence, we expect reflexivity to determine whether any observed relationship between team identity and cross-team innovative behavior is positive (i.e., cooperative intergroup behavior) or negative (i.e., competitive intergroup behavior). Non-reflexive teams are unlikely to develop a sophisticated representation 
of the task environment that includes the resources and uses of the other team (Richter et al., 2006; West, 2000). Consequently, they may view other teams they are dependent upon as threats to their identity and respond in a more competitive and defensive manner by becoming less receptive to cross-team working (Glynn et al., 2010). In contrast, reflexivity equips a highlyidentified team that perceives itself interdependent with another team to engage in more crossteam innovative behavior because reflecting on how to improve teamwork leads a reflexive team to more broadly conceive its goals and to define roles based both on its own and the other team's unique expertise to facilitate productive interactions across the team boundary.

Drawing on this prior work, we propose that for highly interdependent teams, team identity will be associated with either enhanced or reduced cross-team innovative behavior depending upon levels of reflexivity. Teams that are high in perceived interdependence with other teams and are high in team identity and reflexivity will exhibit higher levels of cross-team innovative behavior. In comparison teams that perceive high interdependence with another team but exhibit low reflexivity will be less likely to engage in cross-team innovative behavior when team identity is high. Despite perceiving interdependence with another team, such teams will be shackled by less sophisticated representations of their task environment and so fail see the broader needs to collaborate with others and may even see others as threats discouraging crossteam innovative behavior. As noted above, we do not hypothesize any effects of team identity on cross-team innovative behavior when perceived interdependence is low. Formally:

Hypothesis 2: The association between team identity and cross-team innovative behavior will be moderated by reflexivity and perceived interdependence with another team.

Hypothesis 2a: Team identity will have its strongest positive association with cross-team innovative behavior when reflexivity and perceived interdependence are both high. 
Hypothesis 2b: Team identity will be negatively associated with cross-team innovative behavior when perceived interdependence is high and reflexivity is low.

\section{Method}

\section{Sample and Procedure}

We approached ten Turkish technology companies conducting R\&D activities that were well-known internationally for their innovation efforts. We first contacted senior managers of the firms to obtain their permission for the study. We then contacted R\&D or HR managers of the nine firms that agreed to participate who provided us with the names of the R\&D personnel and their leaders together with the teams they belonged to. We also confirmed with the R\&D or HR managers that innovative behavior was an important part of the formal role of teams we surveyed. On each survey we used codes for employees and team leaders. The surveys were distributed (and returned) in envelopes to assure confidentiality. All scale items used in the questionnaire were back translated with native speakers of English and Turkish also checking the scale items for wording, accuracy and clarity.

As the team formed the primary level of analysis, we examined the representativeness of the data collected at the team level. Using the same selection criterion as described in Richter et al. (2006), we excluded teams with very low group-level response rates from further analysis. This criterion applies a formula which assesses the accuracy of incomplete team data in predicting true scores as a function of number of responses per team $(n)$ and group size $(N)$ using the formula $([N-n] / N n)$. As proposed by Richter et al. (2006), a cut-off point of .32 was employed as values of .32 or lower are generally correlated with true scores at .95 or higher. All teams included in the main analysis were below this proposed cut-off point, and displayed an 
average team level response rate of $67 \%$ (ranging from $38 \%$ to $100 \%$ ). Adopting these criteria eliminated eight teams.

This final sample included 305 team members and 61 team leaders from 61 teams with the average team comprising of seven members. Teams ranged from 3 to 20 members, with 50 of the 61 teams having between 3 and 9 members. Table 1 shows descriptive sample characteristics. Teams participating in the study were all engaged in R\&D work. Hence, all of them were semiautonomous and performed complex tasks that required differential expertise and skills. Team members were physically located in the same unit and typically interacted regularly to achieve shared goals through meetings and more informal interactions. They also had joint responsibilities for accomplishing a set of tasks.

\section{Measures}

All measurement items are provided in the Appendix.

Team identity. As noted above, team identity is a team-level measure of team identification. Team members responded individually on a 5-point response scale $(1=$ strongly disagree, 5 = strongly agree) to four items developed by Doosje, Ellemers and Spears (1995), which were then aggregated to the team level as described below.

Team reflexivity. Team members responded individually on a 5-point response scale $(1=$ strongly disagree, 5 = strongly agree) to six items reported by Somech (2006), which were then aggregated to the team level as described below.

Perceived Team interdependence. Perceived team interdependence was measured by four items with two items adapted from Campion, Medsker, and Higgs (1993) and two items developed by the authors. Team members were first instructed to consider the R\&D team with which their team has collaborated the most but at the same time to some extent competed for 
resources in the last 12 months when completing this scale. Then, they provided their perceptions of interdependence with the other team individually on a 5-point response scale $(1=$ not at all, 5 $=$ very much). Higher scores indicate higher perceived interdependence. Research assistants in the companies were in contact with all the team leaders and members and asked them about the target R\&D team. They assured that everyone in the team referenced the same target team. Individual scores were aggregated as described below.

Team innovative behavior. Team innovative behavior was measured by four items adapted from De Dreu (2006) and one item from Janssen (2000) to fit the technology intensive context. In a separate team leader questionnaire, team leaders evaluated the innovative behavior of their teams during the last 12 months on a 5-point response scale $(1=$ never, $5=$ always $)$.

Cross-team innovative behavior. Cross-team innovative behavior was measured on a six item scale adapted from Richter et al. (2005; 2006). We adapted items from Richter's intergroup effectiveness scale that were relevant to our conceptualization of cross-team innovative behavior which captures exchange of ideas and resources, and coordination of work to facilitate innovation development and implementation across teams. Our items were altered from the original health care context in which they were developed by Richter and colleages to fit the innovation context of our study. Team leaders were instructed to consider the R\&D team with which their team has collaborated the most but at the same time to some extent competed for resources in the last 12 months when completing this particular scale. Team leaders responded on a 5 -point response scale $(1=$ not at all, $5=$ very much $)$.

Control variables. We controlled for team size as previous research has shown its relationship to within-team innovative behavior (see: Hülsheger et al., 2009). We also controlled for team members' average age and gender. Gender was coded $1=$ male $0=$ female, in aggregate 
format it represented the proportion of male respondents within the team. Because our sample consists of teams from organizations performing different types of R\&D tasks we also include controls for three types of teams: a) manufacturing; b) software and c) electronics, and created dummy variables to correspond to these teams.

\section{Results}

\section{Descriptive Statistics}

Table 2 shows the means, standard deviations, inter-correlations and Cronbach alphas of all study variables at the team level. To examine construct distinctiveness we performed confirmatory factor analysis using MPlus software (Muthén and Muthén, 2010) to test competing models at the team level. For the items rated by team members, we first tested a single factor model combining team identity, reflexivity and perceived interdependence. This model exhibited poor fit as anticipated $\left(\chi^{2} 332.03(77)=, p<.01 ; \mathrm{CFI}=.515 ; \mathrm{TLI}=.427 ; \mathrm{RMSEA}=.233\right) . \mathrm{A}$ three factor model exhibited acceptable fit $\left(\chi^{2} 106.54(74)=, p<.01 ;\right.$ CFI = .938; TLI = .924; RMSEA $=.085)$. We also tested competing models of the items rated by team leaders. The first combined team innovative behavior with cross-team innovative behavior and exhibited poor fit $\left(\chi^{2} 148.26(44)=, p<.01 ; \mathrm{CFI}=.634 ; \mathrm{TLI}=.542 ; \mathrm{RMSEA}=.197\right)$. A model testing these as separate factors fit the data acceptably $\left(\chi^{2} 45.28(43)=\right.$, n.s.; CFI = .992; TLI = .990; RMSEA = .029). Overall, we concluded that our measures were appropriate.

\section{Data Aggregation}

To determine whether it was appropriate to aggregate variables to the team level we examined within-team agreement using the Average Deviation $(A D)$ index (Burke, Finkelstein, and Dusing, 1999). The $A D_{M}$ for team identity was 0.47 (SD 0.21$)$, for team reflexivity was 0.44 $(S D$ 0.19), and for perceived interdependence was 0.48 (SD 0.21), indicating acceptable inter- 
rater agreement (Burke and Dunlap (2002) (c/6 where c equals number of response options, so in this case $5 / 6=.83)$. Next, we calculated the $r_{w g(j)}$ statistic, with the mean $r_{w g(j)}$ of 0.90 for team identity, 0.92 for team reflexivity, and 0.88 for perceived interdependence, all comfortably above the 0.7 cutoff proposed by James, Demaree and Wolf $(1984,1993)$. To measure inter-rater reliability we computed intraclass correlation coefficients ICC(1) and ICC(2) with values of 0.20 and 0.55 for team identity, 0.17 and 0.51 for team reflexivity, and 0.27 and 0.65 for perceived interdependence, which are within acceptable limits for applied samples (Bliese, 2000). Taken together the data demonstrated within-team agreement and between-team differences supporting the aggregation of team identity, reflexivity and perceived interdependence to the team level.

We also analyzed whether multi-level modeling should be conducted on the data as it was collected from a number of different organizations. We tested an unconditional model with no predictors that allowed the intercept team to vary by the organization within which the teams were nested. This allowed us to assess the ICC(1) or the proportion of variance in the dependent variable which is at Level-2 (or accounted for by the organization). For each of our dependent variables the intercept was non-significant; therefore we decided to report analysis obtained from linear regression to test the study hypotheses (as this approach allows us to test for slope differences).

\section{Hypothesis Testing}

Table 3 presents a series of regression models with team leader ratings of either team or cross-team innovative behavior as the dependent variable. For both dependent variables we adopted the same approach where the control variables (team size, gender, age, and dummy coded team type) were entered in the first block of the regression (models 1a and 1b, Table 3). All continuous predictor variables were mean-centered (Aiken and West, 1991). Regressions 
using the independent variable team identity (as rated by team members) and the moderating variables of team reflexivity and perceived interdependence (as rated by team members) were entered in the second and third blocks of the regression (models $2 \mathrm{a} / \mathrm{b}$ and $3 \mathrm{a} / \mathrm{b}$, Table 3 ). To test hypothesis 1 we calculated a two-way interaction term as a product of team identity multiplied by team reflexivity and entered this in the fourth block of the regression (model 4a, Table 3 ). To test hypothesis 2 we adopted a similar procedure but this time calculated the three possible twoway interaction terms and entered these in the fourth block of the regression (model 4b, Table 3), and a three-way interaction term was calculated and entered in the fifth block of the regression (model 5b, Table 3). To assist with the interpretation of significant interaction effects we adopted the procedures described by Aiken and West (1991) using points $1 S D$ above ('high') and below ('low') the mean of the moderating variable, and where appropriate, we conducted a simple slope test to test the significance of the 'high' and 'low' slopes of the moderating variable. For the three way interaction effect proposed in hypothesis 2 we adopted the procedures proposed by Dawson and Richter (2006) and examined the differences between pairs of slopes.

Additional analysis was conducted on team size, which can have a curvilinear relationship with innovation (De Dreu, 2006). We entered team size and team size squared into a regression model and found that the squared term was not significantly related to team innovative behavior $(\beta=-.09$, n.s. $)$ or cross-team innovative behavior $(\beta=.05$, n.s. $)$. We also repeated the analyses reported below using team size and the team size squared and retained the basic pattern of results.

Hypothesis 1. Hypothesis 1 proposed reflexivity moderates the effects of team identity on team innovative behavior such that the association between team identity and team innovative behavior is stronger when team reflexivity is high. Results displayed in Table 3 (model 1a) show 
that our control variables accounted for a quarter of the variance in team innovative behavior. A higher proportion of male team members was associated with higher team innovative behavior $(\beta$ $=.41, p<.01)$. Team size $(\beta=-.22, p<.10)$ was marginally related to team innovative behavior. Neither team identity nor reflexivity displayed a significant main effect relationship with team innovative behavior (model 2a, Table 3), however the interaction term between these variables (model 3a, Table 3) was significant $\left(\beta_{\text {interaction }}=.36, p<.01\right)$ and explained 10 percent of the unique variance over and above the main effects $\left(f^{2}=.12\right)$. This effect is depicted in Figure 1 . As hypothesized when team reflexivity was low a non-significant relationship was observed between team identity and team innovative behavior (simple slope test: gradient $-.118, t=-0.63$, n.s.); however, when team reflexivity was high, increasing team identity was significantly positively related to team innovative behavior (simple slope test: gradient $.462, t=2.12, p<.05$ ). These results support Hypothesis 1.

Hypothesis 2. Hypothesis 2 proposed reflexivity and perceived interdependence moderate the association between team identity and cross-team innovative behavior. Specifically we hypothesized that team identity would be positively associated with cross-team innovative behavior when both team reflexivity and perceived interdependence are high $(\mathrm{H} 2 \mathrm{a})$ while team identity would be negatively associated with cross-team innovative behavior when team reflexivity is low and perceived interdependence is high (H2b). Table 3 shows that team identity $(\beta=.34, p<.05)$ was significantly related to cross-team innovative behavior when entered separately (model $2 \mathrm{~b}$, Table 3 ), although when team reflexivity and perceived interdependence were added to the regression this effect became non-significant. The proposed three-way interaction between team identity, reflexivity and perceived interdependence was significant as 
predicted $\left(\beta_{\text {three-way interaction }}=.51, p<.05\right)($ model $4 \mathrm{~b}$, Table 3$)$ and explained an additional 6 percent of the unique variance over and above the main effects $\left(f^{2}=.15\right)$.

This interaction is depicted in Figures $2 \mathrm{a}$ and $2 \mathrm{~b}$. Supporting H2a, we observed a positive relationship between team identity and cross-team innovative behavior under high levels of team reflexivity and perceived interdependence (bold line). Supporting H2b, where low team reflexivity was coupled with high perceived interdependence (dotted line) a negative relationship was observed between team identity and cross-team innovative behavior in Figure 2a. The Dawson and Richter (2006) methodology reveals a significant difference between these slopes (slope difference test: reflexivity high, perceived interdependence ${ }_{\text {high }} /$ reflexivity low, perceived interdependence high: $t=2.31, p<.05)$. As social identity theory does not offer specific guidance on the pattern of the relationships for teams low in perceived interdependence, we did not formulate any specific hypothesis for such teams. However, in Figure $2 b$ we plot the interaction for low perceived interdependence for completeness. Using the Dawson and Richter (2006) methodology we find that the difference in these slopes was not significant (slope difference test: reflexivity high, perceived interdependence low / reflexivity low, perceived interdependence low: $t=-$ 0.82, n.s.).

\section{Discussion}

In this study, we bring team identity and reflexivity together with team and cross-team innovative behavior to test social identity theory-based predictions of the effects of strong team identity on team-level innovative behavior. Social identity theory proposes that identities motivate behavior perceived to be consistent with maintaining and strengthening them (Ashforth and Mael, 1989). R\&D contexts would seem to be places where innovative behavior would be regarded as identity-consistent (Markham and Lee, 2014; Mascitelli, 2000), yet innovative 
behavior does not always materialize in such settings (Ancona and Caldwell, 1992) and can even come to be seen as illegitimate (Dougherty and Heller, 1994). We hypothesized team reflexivity as a legitimizing influence on the identity-consistency of team innovative behavior based on its construct definition and underlying roots linked to the relationship between professional identities and adaptive behavior (Schön, 1983; West 2000). We further observed that reflexivity embodies the balance between respect for individual differentiation that underlies creative motivation (Janssen and Huang, 2008) and collective inclusion that is required for team-level motivation (Ellemers et al., 2004) as found in the social identity concept of optimal distinctiveness (for review, see Leonardelli et al., 2010). In line with our theorizing of this interaction between team identity and team reflexivity, we found that teams high in team identity engaged in more team innovative behavior when they were high, but not low, in team reflexivity. Social identity theories and innovation research have each noted differences between intra-team and interteam behavior. We separately measured cross-team innovative behavior and examined the generalization of the team identity x reflexivity interaction to this new dependent variable. The fact that interteam behaviors have long been recognized to depend on perceived interteam interdependence (e.g., Sherif et al., 1961) suggested a threeway interaction between team identity, reflexivity, and perceived interdependence wherein we expected the team identity $\mathrm{x}$ reflexivity interaction to affect cross-team innovative behavior only when teams perceived interteam interdependence. Moreover, intergroup effectiveness theory (e.g., Richter et al., 2005; 2006) and prior research by Glynn et al. (2010) showing destructive effects of intergroup threat on individuals' innovation intentions led us to hypothesize that team identity's effects on crossteam innovative behavior in interdependent teams would shift from positive to negative as reflexivity declined. As predicted, team identity was associated with enhanced cross-team 
innovative behavior when reflexivity was high and with reduced cross-team innovative behavior under low reflexivity, with these effects occurring only when perceived interteam interdependence was high. Our analyses document how team identity's effects on innovative behavior can shift from benign to malignant as the focus shifts from team- to cross-team when reflexivity is low and teams perceive interdependence with other teams.

\section{Theoretical Implications}

Our work makes two primary contributions to theory. First, our study illustrates how team identity and reflexivity can interact and in so doing clarifies the conditions for team identity to foster team-level innovative behavior. Social identity theory posits that behaviors must be perceived as identity-consistent to be motivated; our research explains how innovative behaviors may come to be perceived as supporting a strong team identity in innovation contexts. Digging into the theoretical foundations of team reflexivity, we find an underlying rationale for how differences in team reflection can affect whether and how team identity is energized toward innovative behavior in $R \& D$ contexts. Prior research has found that successful product innovation often requires reframing of tasks and problems in order for innovative behavior to be seen as a legitimate activity (Dougherty and Heller, 1994); reflexive teams show a willingness to engage with such reframing (West, 2000). Although prior research has pursued social identity (Hirst et al., 2009a) and reflexivity (Tjosvold et al., 2004) independently, we believe that reflexivity's effect on teams' definitions of identity-consistent behavior provides a compelling basis for at least one type of integration of these two constructs by explaining when highly identified teams will welcome novelty. Theory and research on team innovation may benefit by 
moving from considering identity and reflexivity in isolation to conceptualizing their interaction as a foundational element of team innovative behavior.

Our second contribution is to demonstrate the value of specifically theorizing and measuring innovative behavior as both a within-team and cross-team phenomenon. Although there are a few studies examining interteam coordination, boundary activities, or knowledge sharing activities, their focus was not on innovative behavior across the team boundary (DrachZahavy and Somech, 2010; Hoegl, Weinkauf, and Gemuenden, 2004; Markham and Lee, 2014). To our knowledge, this is the first study examining the effects of team identity on both team and cross-team innovative behavior. Analyzing the effects of both types of innovative behavior allows a more thorough analysis using a social identity lens in environments where multiple teams are at work, and it also allows a deeper look at the interteam contexts that prior innovation research has found to be most challenging for predicting how psychological attachment will translate into innovative behavior (Ancona and Caldwell, 1992; Glynn et al., 2010). Our observation of both positive and negative effects of team identity on cross-team innovative behavior in interdependent teams shows that team reflexivity is all the more important when cooperation is wanted between teams. The fact that the generalizability of the team identity $\mathrm{x}$ reflexivity interaction was contingent upon perceived interteam interdependence is also a reminder that even in multiteam $R \& D$ contexts where interdependence is structurally present, teams can and do vary in their perceptions of it and these perceptions do matter (Glynn et al., 2010). Our work elaborates and enhances the conclusions of prior work (Glynn et al., 2010) by showing the upside and downside of the combination of high team identification and high perceived interteam interdependence and, importantly, by articulating reflexivity as a bridge between these two types of effects. We move beyond previous studies by illustrating that in 
multi-team contexts, team identity, reflexivity and perceived structure all play out crucial roles in predicting innovative behavior.

Given that we found evidence of both positive and negative effects of team identity on cross-team innovative behavior, future research might particularly focus on rectifiying the dearth of literature on support for teams in multiteam contexts (Barczak et al., 2009) by exploring structural interventions that increase the likelihood that team identity and reflexivity will function to enhance innovative behavior. The positive effect of the combination of high identity, reflexivity, and perceived interdependence in our study is consistent with both of the key social identity mechanisms for spurring positive intergroup behavior - superordinate identity formation (Richter et al., 2006) and mutual differentiation through roles based on expertise (Gaertner et al., 2000; Hewstone and Brown, 1986). A traditional approach to help groups resolve their competing impulses in intergroup situations is to facilitate cooperation with others by increasing the salience of a larger, more inclusive identity (such as an organization or project; Richter et al., 2006). This larger identity then provides the "why" for cooperation that enables productive intergroup behavior. However, such larger identities are not always available, and local identities (i.e., team identity) may outweigh more inclusive identities as an influence (Brewer, 1996; Dougherty and Heller, 1994; Glynn et al., 2010). Another long heralded strategy to enhance cooperation between teams is to encourage contact between groups. Yet, contact may not always yield positive consequences which is exactly why our study of reflexive team processes is so important. Our approach opens up a new avenue for research leveraging social identity theory to study innovation. The key is that the group has to be able to see how the contributions of the other team can be facilitative of its local interests and goals through reflexivity. In particular, we suggest that an adaptive function of reflexivity may be to promote reflection about the roles 
played by each team and thus ease the path to cross-team innovative behavior. Hence, future theory and research might particularly examine managerial actions aimed at highlighting or defining complementary roles between teams.

\section{Managerial Implications}

Although organizations invest considerable effort seeking to develop strong team identities, the development of such identities does little to benefit innovative behavior and can actually harm it across teams if unaccompanied by collective reflection. One of the managerial practices to increase both team identity and reflexivity may be to encourage participation in team-related decisions. Reflexivity can be enhanced by encouraging open discussion, requesting all individuals share dissenting ideas without fear of retribution or criticism or guiding the members to reflect on what they have done so far. Moreover, leaders may encourage constructive controversy (Tjosvold et al., 2004) where they have the opportunity to discuss team-related issues and actively seek information and feedback both within and outside the team. Through such an exchange, teams can build upon each other's know-how and enhance their innovation capabilities collectively. Given the importance and prevalence of interdependent teams, managers can act as a bridge between teams, encourage open discussion, exchange of ideas and cooperation across teams to increase knowledge flows and creative ideas. Interteam leaders should "convey the appropriate inter-group relational message by using compelling identity rhetoric and by building boundary-spanning relationships" (Hogg, van Knippenberg, and Rast, 2012, p. 250).

\section{Limitations and Directions for Future Research}

Our study was conducted among R\&D teams from a variety of organizations. The effect sizes for our hypotheses are consistent with those found for interactions and are in fact above the 
normal thresholds for field research (Aguinis, Beaty, Boik, and Pierce, 2005; Cohen, Cohen, West, and Aiken, 2003; Dawson, 2014; McClelland and Judd, 1993). Nevertheless, our study has limitations. Obviously, our results only pertain to environments where cross-team innovative behavior is a meaningful option. Although our use of multiple sources of data and our focus on interaction hypotheses mean that common method bias is not a concern, the cross-sectional design does not allow examination of causality. Research has suggested that reflexivity may be especially important at the initial stages of innovation projects (e.g., Hoegl and Parboteeah, 2006; Schippers, Den Hartog, Koopman, and Wienk, 2003). Team identity might also have different effects on idea generation in the initial stages and on implementation in the later stages of innovative projects. Therefore, future research should include longitudinal studies. We framed our investigation in terms of social identity and posited team reflexivity as a moderator, but reflexivity is an empirically equivalent focus. Future research might adopt reflexivity as a focus in order to integrate our work with other emerging insights into reflexivity's effects on innovation (e.g., Schippers et al., 2015). Furthermore, although we focused on positive effects of reflexivity, it may be less helpful in some situations such as in the case of low perceived interdependence (and high identity) in the present study. There may also be other cases where reflexivity is costly since it requires time and energy. For instance, when the size of the team gets larger, especially in teams operating under a relatively high pressure to innovate, team processes may get poorer due to potential process losses such as social loafing, communication difficulties, or lower levels of participation (Curral, Forrester, Dawson, and West, 2001). Therefore, reflexivity in large groups (above 12 or 13 according to Poulton, 1995) may have higher costs than its benefits as compared to smaller teams, as in the present study (mean team size: 7.5 , the correlation between team size and reflexivity was not significant). Hence, future research might 
examine large teams. Moreover, in our study we focused on perceived interdependence between different teams (Glynn et al., 2010). Related literature has proposed a distinction between task and goal interdependence (Drach-Zahavy and Somech, 2010). Future research can study the effects of these interdependence types in cross-team innovation to foster organizational effectiveness. Although Richter et al. (2005) provided evidence that a single team's measure can suffice to examine boundary spanning questions, future work might address the intergroup context by considering groups as joint raters of intergroup variables or by taking a round-robin perspective and examining reciprocity in group perceptions and behaviors. Finally, it may be interesting to examine how different interteam boundary activities impact cross-team innovative behavior. Previous research suggested that task coordinator activities, such as coordinating technical or design issues, discussing problems with others, obtaining feedback and negotiating with outsiders, benefit team innovation (Ancona and Caldwell, 1992; Drach-Zahavy and Somech, 2010). Future researchers may examine the moderating effects of such interteam boundary activities in team identity-cross-team innovative behavior link. Who - team leaders or all team members - should carry out these activities across teams is also to be explored.

Organizations are increasingly seeking to leverage team innovative behaviors to attain broader organizational outcomes. This research illustrates that practices that seek to build strong team identities do little to enhance innovative behavior on their own. Rather identity in conjunction with reflection is core not just to team, but also cross-team innovative behavior especially for highly interdependent teams. Such knowledge provides the necessary foundation to translate innovation to the broader organizational context. 


\section{Appendix. Questionnaire Items}

Team identity is measured by 4-items from Doosje, Ellemers and Spears (1995).

1. I see myself as a member of this team

2. I am pleased to be a member of this team

3. I feel strong ties with members of my team

4. I identify with other members of my team

Team reflexivity is measured by 6 items from Somech (2006).

1. In the team, we always look for different interpretations and perspectives to confront a problem

2. In the team, we criticize each others' work in order to improve team effectiveness

3 . In the team, we are prepared to reflect on the way we act

4. In the team, we engage in evaluating our weak points in attaining effectiveness

5 . In the team, we openly challenge each others' opinions

6 . In the team, we reassess any proposed solution

Team perceived interdependence is measured by 2 -items adapted from Campion, Medsker, and Higgs (1993) and the last 2-items developed by the authors.

1. To what extent are these two teams dependent on each other in doing their work?

2. To what extent are jobs performed by these two teams related to each other?

3. To what extent do these two teams have to get information or materials from each other to accomplish their tasks?

4. To what extent do these two teams meet to talk about work-related issues?

Team innovative behavior is measured by 4-items from De Dreu (2006) and one item from Janssen (2000)

1. Team members often implemented new ideas to improve the quality of our products and services

2. This team gave a lot of consideration to new and alternative methods and procedures for doing their work

3. Team members often produced new services, methods, or procedures

4. This was an innovative team

5. This team created new ideas for difficult issues

Cross-team innovative behavior is measured by 6-items adapted from Richter, Scully, and West (2005; see also Richter, West, van Dick, and Dawson, 2006).

1. To what extent did both teams work effectively together in order to enhance organizational innovation?

2. To what extent did both teams make effective use of each other's innovative ideas?

3. To what extent did both teams work effectively together in order to respond to problems or flaws that emerged from working within the organization (e.g., staff or time shortage, etc.)?

4. To what extent did both teams work effectively together in order to implement new innovation practices across the organization (e.g., coordinating cross-team activities, assignment of organizational duties, etc.)?

5. To what extent did both teams effectively help each other out if resources (e.g. time to invest, people or staff, support etc.) were needed to facilitate the implementation of new innovations? 6. To what extent did you feel the relationship between the two teams enhanced organizational innovation? 


\section{References}

Adarves-Yorno, I., T. Postmes, and S. A. Haslam. 2006. Social identity and the recognition of creativity in groups. Biritish Journal of Social Psychology 45 (3): 479-497.

Aguinis, H., J. C. Beaty, R. J. Boik, and C. A. Pierce. 2005. Effect size and power in assessing moderating effects of categorical variables using multiple regression: A 30-year review. Journal of Applied Psychology 90 (1): 94-107.

Aiken, L.S., and S.G. West. 1991. Multiple regression: Testing and interpreting interactions. Newbury Park, CA: Sage.

Amabile, T.M. 1988. A model of creativity and innovation in organizations. In Research in Organizational Behavior (Volume 10), ed. B. M. Staw and L. Cummings, 123-167. Greenwich, CT: JAI Press.

Ancona, D. G., and D. F. Caldwell. 1992. Bridging the boundary: External activity and performance in organizational teams. Administrative Science Quarterly 37 (4): 634-665.

Anderson, N., K. Potocnik, and J. Zhou. (2014). Innovation and creativity in organizations: A state-of-the-science review, prospective commentary, and guiding framework. Journal of Management 40 (5): 1297-1333..

Argyris, C., 1991. Teaching smart people how to learn. Harvard Business Review 69 (3): 99-109.

Argyris, C. 1993. Knowledge for action: A guide to overcoming barriers to organizational change. San Francisco: Jossey-Bass.

Ashforth, B. E., and F. Mael. 1989. Social identity theory and the organization. Academy of Management Review 14 (1): 20-39. 
Barczak, G., A. Griffin, and K. B. Kahn. 2009. Trends and drivers of success in NPD practices: Results of the 2003 PDMA best practices study. Journal of Product Innovation Management $26(1): 3-23$.

Bliese, P. D. 2000. Within-group agreement, non-independence, and reliability: Implications for data aggregation and analyses. In Multilevel theory, research, and methods in organizations: Foundations, extensions, and new directions, ed. K. J. Klein and S. W. J. Kozlowski, 349381. San Francisco, CA: Jossey-Bass.

Brewer, M. B. 1996. When contact is not enough: Social identity and intergroup cooperation. International Journal of Intercultural Relations 20 (3-4): 291-303.

Brewer, M. B., and W. Gardner. 1996. Who is this "we"? Levels of collective identity and self representations. Journal of Personality and Social Psychology 71 (1): 83-93.

Burke, M. J., and W. P. Dunlap. 2002. Estimating interrater agreement with the average deviation index: A user's guide. Organizational Research Methods 5 (2) 159-172.

Burke, M. J., L. M. Finkelstein, and M. S. Dusig. 1999. On average deviation indices for estimating interrater agreement. Organizational Research Methods 2 (1): 49-68.

Campion, M. A., G. J. Medsker, and A. C. Higgs. 1993. Relations between work group characteristics and effectiveness: Implications for designing effective work groups. Personnel Psychology 46 (4): 823-850.

Cohen, J., P., Cohen, S. G. West, and L. S. Aiken, 2003. Applied multiple regression/correlation analysis for the behavioral sciences. Mahwah, $\mathrm{NJ}$ : Erlbaum.

Curral, L. A., R. H. Forrester, J. F. Dawson, and M. A. West. (2001). It is what you do and the way that you do it. Team task, team size, and innovation-related group processes. European Journal of Work and Organizational Psychology 10 (2): 187-204. 
Dawson, J. F. 2014. Moderation in management research: What, why, when, and how. Journal of Business and Psychology 29 (1): 1-19.

Dawson, J. F., and A. W. Richter. 2006. Probing three-way interactions in moderated multiple regression: Development and application of a slope difference test. Journal of Applied Psychology 91 (4) : 917-926.

De Dreu, C. K. W. 2006. When too little or too much hurts: Evidence for a curvilinear relationship between task conflict and innovation in teams. Journal of Management 32(1): $83-107$.

Doosje, B., N. Ellemers, and R. Spears. 1995. Perceived intragroup variability as a function of group status and identification. Journal of Experimental Social Psychology 31 (5): 410-436.

Dougherty, D., and T. Heller. 1994. The illegitimacy of successful product innovation in established firms. Organization Science 5 (2): 200-218.

Drach-Zahavy, A., and A. Somech. 2010. From an intrateam to an interteam perspective of effectiveness: The role of interdependence and boundary activities. Small Group Research 41 (2), 143-174.

Ellemers, N., D. De Gilder, and S. A. Haslam. 2004. Motivating individuals and groups at work: A social identity perspective on leadership and group performance. Academy of Management Review 29 (3): 459-478.

Faraj, S., and A. Yan. 2009. Boundary work in knowledge teams. Journal of Applied Psychology, 94 (3), 604-617.

Gaertner, S. L., J. F. Dovidio, B. S. Banker, M. Houlette, K. M. Johnson, and E. A. McGlynn. 2000. Reducing intergroup conflict: From superordinate goals to decategorization, 
recategorization, and mutual differentiation. Group Dynamics: Theory, Research, and Practice 4 (1): 98-114.

Glynn, M. A., R. Kazanjian, and R. Drazin. 2010. Fostering innovation in complex product development settings: The role of team member identity and interteam interdependence. Journal of Product Innovation Management 27 (7): 1082-1095.

Goncalo, J. A., and B. M. Staw. 2006. Individualism-collectivism and group creativity. Organizational Behavior and Human Decision Processes 100 (1): 96-109.

Gong, Y., T. Y. Kim, D. R. Lee, and J. Zhu 2013. A multilevel model of team goal orientation, information exchange, and creativity. Academy of Management Journal 56 (3): 827-851.

Gundlach, M., S. Zivnuska, and J. Stoner. 2006. Understanding the relationship between individualism-collectivism and team performance through an integration of social identity theory and the social relations model. Human Relations 59 (12): 1603-1632.

Hargadon, A. B. 1998. Firms as knowledge brokers: Lessons in pursuing continuous innovation. California Management Review, 40, 209-227.

Haslam, S.A. 2004. Psychology in organizations: The social identity approach. London, UK: Sage.

Hewstone, M., and R. J. Brown. 1986. "Contact is not enough: An intergroup perspective on the contact hypothesis". In Contact and conflict in intergroup encounters, ed. M. Hewstone and R. J. Brown, 1-44. Oxford, England: Basil Blackwell

Hewstone, M., M. Rubin, and H. Willis. 2002. Intergroup bias. Annual Review of Psychology 53 (1): 575-604.

Hirst, G., R. van Dick, and D. van Knippenberg. 2009a. A social identity perspective on leadership and employee creativity. Journal of Organizational Behavior 30 (7): 963-982. 
Hirst, G., D. van Knippenberg, and J. Zhou. 2009b. A cross-level perspective on employee creativity: Goal orientation, team learning behavior, and individual creativity. Academy of Management Journal 52 (2): 280-293.

Hoegl, M., and K.P. Parboteeah. 2006. Team reflexivity in innovative projects. $R \& D$ Management 36 (2): 113-125

Hoegl, M, K. Weinkauf, and H. G. Gemuenden. 2004. Interteam coordination, project commitment, and teamwork in multiteam R\&D projects: A longitudinal study. Organization Science 15 (1): 38-55.

Hogg, M. A., and D.I. Terry. 2000. Social identity and self-categorization processes in organizational contexts. Academy of Management Review 25 (1): 121-140.

Hogg, M. A., D. van Knippenberg, and D.E. Rast. 2012. Intergroup leadership in organizations: Leading across group and organizational boundaries. Academy of Management Review 37 (2): 232-255.

Hülsheger, U. R., N. Anderson, and J. F. Salgado. 2009. Team-level predictors of innovation at work: A comprehensive meta-analysis spanning three decades of research. Journal of Applied Psychology 94 (5): 1128-1145.

James, L. R., R. G. Demaree, and G. Wolf. 1984. Estimating within-group interrater reliability with and without response bias. Journal of Applied Psychology 69 (1): 85-98.

James, L. R., R. G. Demaree, and G. Wolf. 1993. rwg: An assessment of within-group interrater agreement. Journal of Applied Psychology 78 (2): 306-309.

Janssen, O. 2000. Job demands, perceptions of effort-reward fairness and innovative work behavior. Journal of Occupational and Organizational Psychology 73 (3): 287-302. 
Janssen, O., and X. Huang. 2008. Us and me: team identification and individual differentiation as complementary drivers of team members' citizenship and creative behaviors. Journal of Management 34 (1): 69-88.

Kahn, W. A. 1992. To be fully there: Psychological presence at work. Human Relations 45 (4): 321-349.

Lembke, S., and M. G. Wilson. 1998. Putting the 'team' into teamwork: Alternative theoretical contributions for contemporary management practice. Human Relations 51 (7): 927-944.

Leonardelli, G. J., C. L. Pickett, and M. B. Brewer. 2010. Optimal distinctiveness theory: A framework for social identity, social cognition, and intergroup relations. Advances in Experimental Social Psychology 43: 63-113.

Markham, S. K. and H. Lee. 2014. Marriage and family therapy in NPD teams: Effects of weness on knowledge sharing and product performance. Journal of Product Innovation Management 31 (6): 1291-1311.

Marrone, J. A. 2010. Team boundary spanning: A multi-level review of past research and proposals for the future. Journal of Management, 36, 911-940.

Mascitelli, R. 2000. From experience: Harnessing tacit knowledge to achieve breakthrough innovation. Journal of Product Innovation Management 17 (3) 179-193.

Mathieu, J. E., M. A. Marks, and S. J. Zaccaro. 2001. Multi-team systems. In Handbook of industrial, work and organizational psychology, ed. N. Anderson, D. S Ones, H. K: Sinangil and C. Viswesvaran, 289-313. London, UK: Sage.

McClelland, G. H., and C. M. Judd. 1993. Statistical difficulties of detecting interactions and moderator effects. Psychological Bulletin 114 (2): 376-390.

Mitchell, R. J., V. Parker, and M. Giles. (2011). When do interprofessional teams succeed? 
Investigating the moderating roles of team and professional identity in interprofessional effectiveness. Human Relations, 64(10) 1321-1343.

Morgeson, F. P., and D. A. Hofmann. 1999. The structure and function of collective constructs: Implications for multilevel research and theory development. Academy of Management Review 24 (2):249-265.

Muthén, L. K., and B. O. Muthén. 1998-2010. Mplus User's Guide. Los Angeles, CA: Muthén and Muthén.

Petriglieri, J. L. 2011. Under threat: Responses to and the consequences of threats to individuals' identities. Academy of Management Review, 36 (4): 641-662.

Pettigrew, T. F., and L. R. Tropp. 2006. A meta-analytic test of intergroup contact theory. Journal of Personality and Socila Psychology, 90 (5): 751-783.

Poulton, B. C. 1995. Effective multi-disciplinary teamwork in primary healthcare. Unpublished doctoral thesis, Institute of Work Psychology, University of Sheffield, UK.

Richter, A. W., J. W. Scully, and M. A. West. 2005. Intergroup conflict and intergroup effectiveness in organizations: Theory and scale development. European Journal of Work and Organizational Psychology 14 (2): 177-203.

Richter, A. W., M. A. West, R. van Dick, and J. F. Dawson. 2006. Boundary spanners' identification, intergroup contact, and effective intergroup relations. Academy of Management Journal 49 (6): 1252-1269.

Schippers, M. C., D .N. Den Hartog, P. L. Koopman, and J. A. Wienk. 2003. Diversity and team outcomes: The moderating effects of outcome interdependence and group longevity and the mediating effect of reflexivity. Journal of Organizational Behavior 24 (6): 779-802. 
Schippers, M. C., M. A. West, and J. D. Dawson. 2015. Team reflexivity and innovation: The moderating role of team context. Journal of Management 41 (3) 769-788.

Schön, D. 1983. The reflective practitioner. New York: Basic Books.

Sherif, M., O. J. Harvey, B. J. White, W. R. Hood, and C. W. Sherif. 1961. Intergroup conflict and cooperation: The Robbers Cave experiment. Norman: University of Oklahoma Book Exchange.

Sivasubramaniam, N., S. J. Liebowitz, and C. Lackman. 2012. Determinants of new product development team performance: A meta-analytic review. Journal of Product Innovation Management 29 (5): 803-820.

Somech, A. 2006. The effects of leadership style and team process on performance and innovation in functionally heterogeneous teams. Journal of Management 32 (1): 132-157.

Somech, A., H. S. Desivilya, and H. Lidogoster. 2009. Team conflict management and team effectiveness: The effects of task interdependence and team identification. Journal of Organizational Behavior 30 (3): 359-378.

Tajfel, H., and J. C. Turner. 1986. The social identity theory of intergroup behavior. In Psychology of intergroup relations, ed. S. Worchel and W.G. Austin, 7-24. Chicago, IL: Nelson-Hall.

Tjosvold, D., M. M. L. Tang, and M.A. West. 2004. Reflexivity for team innovation in China: The contribution of goal interdependence. Group and Organization Management 29 (5): 540559.

van Knippenberg, D., and E. C. M. van Schie. 2000. Foci and correlates of organizational identification. Journal of Occupational and Organizational Psychology 73 (2): 137-147.

West, M.A. 1996. The handbook of work group psychology. Chichester, UK: John Wiley. 
West, M. A. 2000. Reflexivity, revolution, and innovation in work teams. In Advances in the interdisciplinary study of work teams: Product development teams. ed. M.M. Beyerlein, D.A.Johnson and S.T. Beyerlein, 1-29. Stamford, Connecticut: JAI Press.

West, M. A. 2002. Sparkling fountains or stagnant ponds: An integrative model of creativity and innovation implementation in work groups. Applied Psychology: An International Review 51 (3): $355-424$.

West, M.A., and J.L. Farr. 1990. Innovation at work. In. Innovation and creativity at work: Psychological and organizational strategies. ed. M. A West, and J. L. Farr, 3-13. Chichester, UK: Wiley. 
Table 1

Sample Descriptive Characteristics

\begin{tabular}{|l|c|l|c|}
\hline \multicolumn{1}{|c|}{ Industry } & \% & \multicolumn{1}{c|}{ Age } & \\
\hline Manufacturing & 28 & Mean & 29.62 \\
\hline Software & 33 & SD & 3.81 \\
\hline Electronics & 39 & Minimum & 24.00 \\
\hline & & Maximum & 44.29 \\
\hline Gender & $\%$ & Education & $\%$ \\
\hline Male & 81 & Undergraduate & 56 \\
\hline Female & 19 & Post-graduate & 41 \\
\hline
\end{tabular}




\section{Table 2}

Means, Standard Deviations and Intercorrelations between Study Variables

\begin{tabular}{|c|c|c|c|c|c|c|c|c|c|c|c|c|c|c|}
\hline & & Mean & SD & 1 & 2 & 3 & 4 & 5 & 6 & 7 & 8 & 9 & 10 & 11 \\
\hline 1 & Team size & 7.54 & 3.82 & -- & & & & & & & & & & \\
\hline 2 & Gender $^{\mathrm{a}}$ & 0.81 & 0.23 & .04 & -- & & & & & & & & & \\
\hline 3 & Age & 29.62 & 3.81 & .00 & .03 & -- & & & & & & & & \\
\hline 4 & Team type (manufacturing) ${ }^{\mathrm{b}}$ & 0.28 & 0.45 & -.13 & .06 & .04 & -- & & & & & & & \\
\hline 5 & Team type (software) ${ }^{b}$ & 0.33 & 0.47 & -.05 & .13 & .12 & $-.43 * *$ & -- & & & & & & \\
\hline 6 & Team type (electronics) ${ }^{\mathrm{b}}$ & 0.39 & 0.49 & .17 & -.18 & -.15 & $-.50 * *$ & $-.56 * *$ & -- & & & & & \\
\hline 7 & Team identity $^{\mathrm{c}}$ & 3.74 & 0.53 & -.04 & $.24^{\dagger}$ & -.11 & $-.23^{\dagger}$ & .12 & .10 & $(.85)$ & & & & \\
\hline 8 & Team reflexivity $^{\mathrm{c}}$ & 3.27 & 0.48 & .01 & $.26 *$ & -.17 & -.19 & -.08 & $.25^{\dagger}$ & $.54 * *$ & $(.83)$ & & & \\
\hline 9 & Team perceived interdependence ${ }^{c}$ & 3.22 & 0.55 & .07 & -.12 & $-.23^{\dagger}$ & $-.25^{\dagger}$ & -.10 & $.33 *$ & .08 & .19 & $(.86)$ & & \\
\hline 10 & Team innovative behavior ${ }^{\mathrm{d}}$ & 3.79 & 0.67 & -.21 & $.39 * *$ & -.18 & .04 & .04 & -.08 & $.24^{\dagger}$ & $.27^{*}$ & .03 & $(.87)$ & \\
\hline 11 & Cross-team innovative behavior ${ }^{\mathrm{d}}$ & 2.97 & 0.84 & -.02 & .12 & -.10 & $-.27 *$ & .15 & .10 & $.41 * *$ & $.42 * *$ & $.32 *$ & .21 & $(.90)$ \\
\hline
\end{tabular}

Notes $^{\mathrm{a}}$ proportion of male respondent in team; ${ }^{\mathrm{b}}$ proportion of teams which were classified as manufacturing, software or electronics team; ${ }^{\mathrm{c}}$ as

rated by team members; ${ }^{\mathrm{d}}$ as rated by team leaders. (Reliabilities in parentheses) $\mathrm{N}=61$ teams ${ }^{\dagger} p<.10 * p<.05 * * p<.01$ 


\section{Table 3}

Results of Regression Analysis for Hypotheses 1 and 2 with Dependent Variables Team Innovative Behavior and Cross-team Innovative Behavior

\begin{tabular}{|c|c|c|c|c|c|c|c|c|c|}
\hline & \multicolumn{4}{|c|}{ Team innovative behavior } & \multicolumn{5}{|c|}{ Cross-team innovative behavior } \\
\hline Team size & $-.22^{\dagger}$ & $-.21^{\dagger}$ & $-.21^{\dagger}$ & -.17 & -.05 & -.03 & -.03 & -.07 & -.12 \\
\hline Gender $^{\mathrm{a}}$ & $.41 * *$ & $.37 * *$ & $.35 * *$ & $.46^{* *}$ & .14 & .05 & .02 & .10 & .05 \\
\hline Age & -.19 & -.18 & -.17 & -.18 & -10 & -.06 & .01 & .08 & .10 \\
\hline Team type (software) ${ }^{b}$ & .00 & -.03 & -.03 & -.01 & $.30^{\dagger}$ & .22 & .19 & .24 & .18 \\
\hline Team type (electronics) ${ }^{\mathrm{b}}$ & .01 & -.03 & -.06 & -.03 & $.29^{\dagger}$ & .20 & .05 & .13 & .12 \\
\hline \multicolumn{10}{|c|}{ Model 3: Moderator variable(s) } \\
\hline Team reflexivity $(\mathrm{RX})^{\mathrm{c}}$ & & & .12 & .19 & & & $.25^{\dagger}$ & .23 & .19 \\
\hline
\end{tabular}


Team perceived

interdependence $(\mathrm{IN})^{\mathrm{c}}$

\section{Model 4: Two-way interaction(s)}

ID $x$ RX

ID $x$ IN

$\mathrm{RX} \times \mathrm{IN}$

Model 4: Three-way interactions

ID $x \mathrm{RX} \times$ IN

\begin{tabular}{lccccccccc}
\hline Change R & due to step \\
Total R R $\mathbf{R}^{2}$ explained & $0.24^{* *}$ & 0.01 & 0.01 & $0.10^{* *}$ & 0.10 & $0.10^{*}$ & $0.11^{*}$ & 0.05 & $0.06^{*}$ \\
& 0.24 & 0.25 & 0.26 & 0.36 & 0.10 & 0.20 & 0.31 & 0.37 \\
\hline
\end{tabular}

Notes ${ }^{\mathrm{a}}$ proportion of male respondent in team; ${ }^{\mathrm{b}}$ referent group manufacturing teams ${ }^{\mathrm{c}}$ as rated by team members.

$\mathrm{N}=61$ teams ${ }^{\dagger} p<.10 * p<.05 * * p<.01$ 


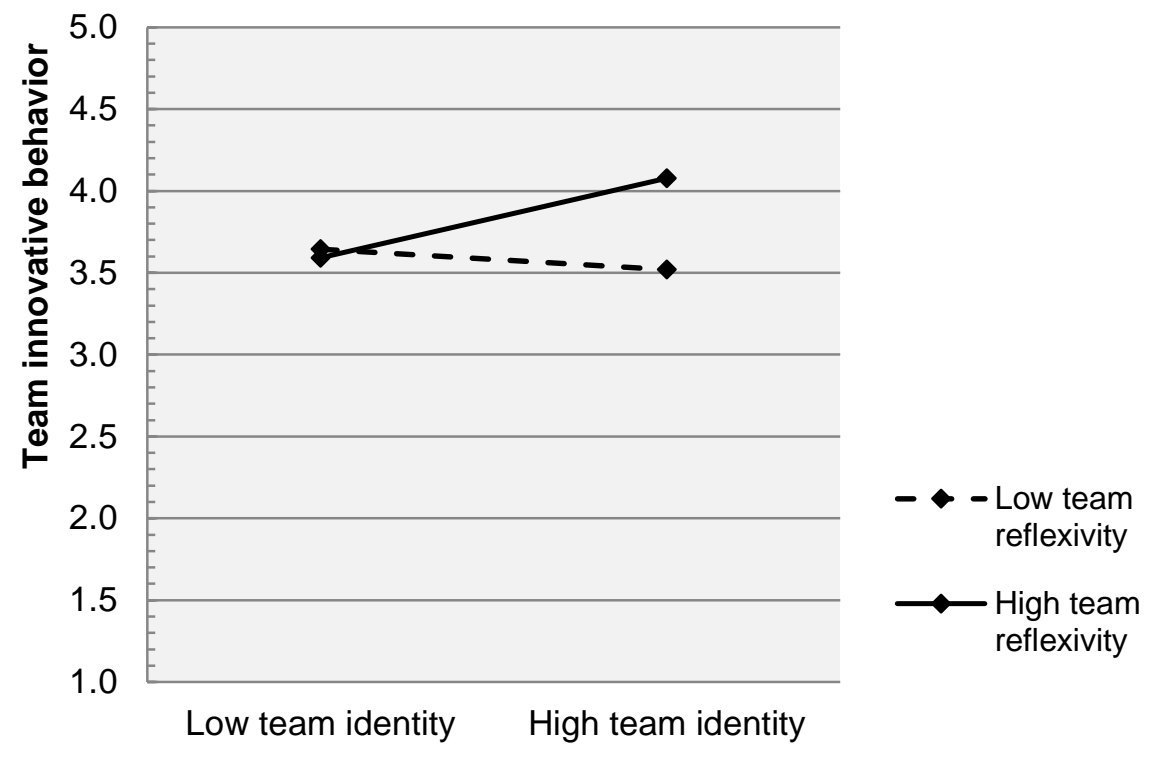

Figure 1. Moderating effect of team reflexivity on the relationship between team identity and team innovative behavior (Hypothesis 1). 


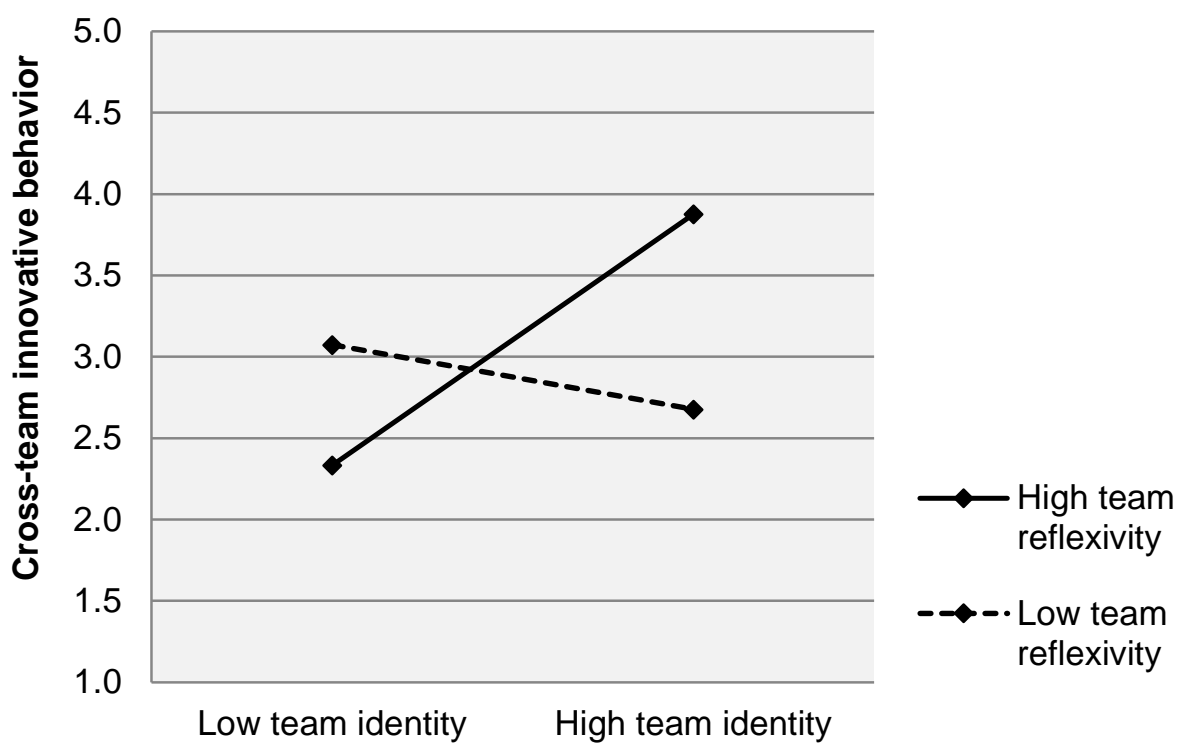

Figure 2a: Moderating effect of team reflexivity on the relationship between team identity and cross-team innovative behavior when perceived interteam interdependence is high (Hypothesis 2a and 2b).

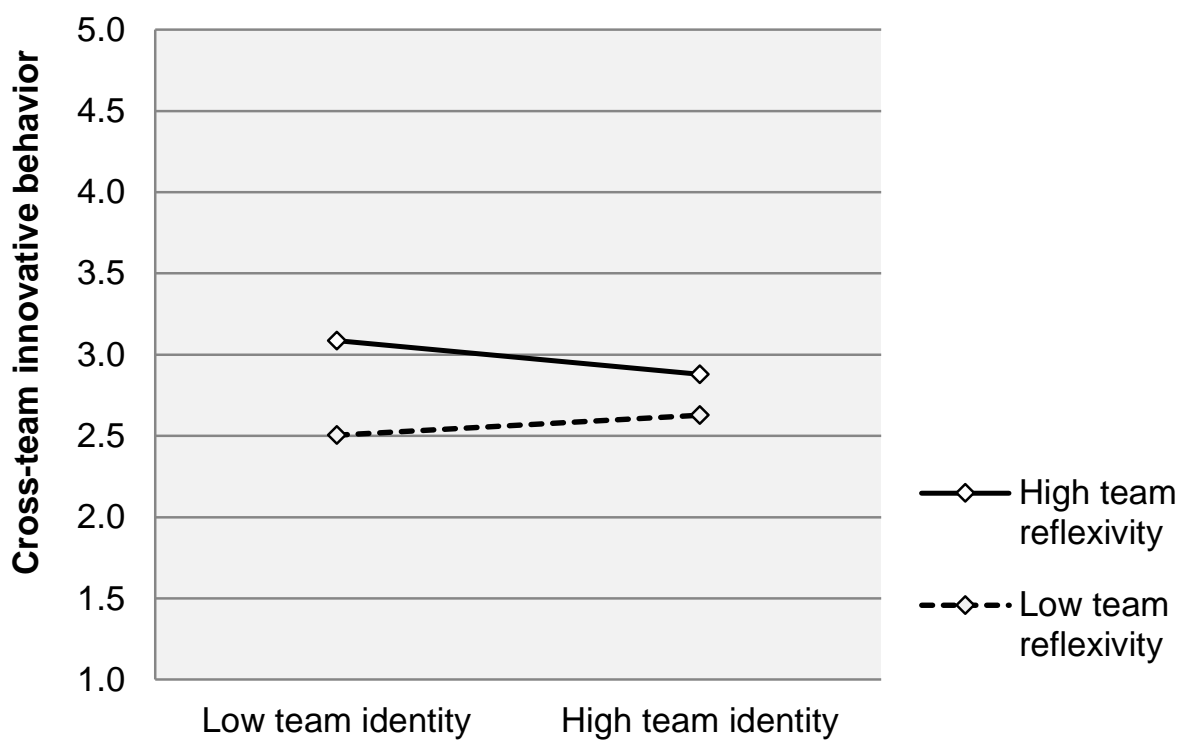

Figure 2b: Moderating effect of team reflexivity on the relationship between team identity and cross-team innovative behavior when perceived interteam interdependence is low. 